\title{
A PROSPECTIVE STUDY TO FIND THE ASSOCIATION BETWEEN POOR POSTNATAL WEIGHT GAIN AND SEVERE RETINOPATHY OF PREMATURITY
}

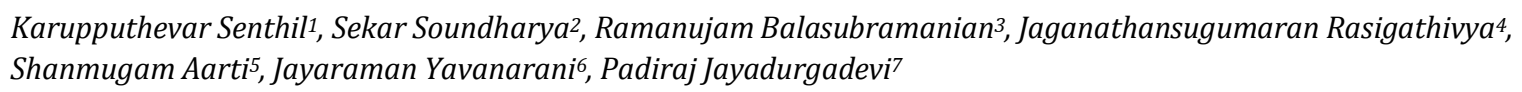

${ }^{1}$ Associate Professor, Department of Diabetology, Madurai Medical College, Madurai.

2Senior Resident, Department of Ophthalmology, Madurai Medical College, Madurai.

3Junior Resident, Department of Ophthalmology, Madurai Medical College, Madurai.

4Junior Resident, Department of Ophthalmology, Madurai Medical College, Madurai.

5Junior Resident, Department of Ophthalmology, Madurai Medical College, Madurai.

6Junior Resident, Department of Ophthalmology, Madurai Medical College, Madurai.

7 Junior Resident, Department of Ophthalmology, Madurai Medical College, Madurai.

\begin{abstract}
BACKGROUND
ABSTRACT

Retinopathy of Prematurity (ROP) is one of the leading causes of preventable childhood blindness in India, incidence is between 38 - 52\% among low birth weight babies. With improved neonatal care and better survival rate of preterm infants, ROP incidence in our country is on the increasing trend. Identifying a modifiable postnatal risk factor like "poor postnatal weight gain" by simple serial postnatal weight measurements helps in identification of premature babies at risk for developing "severe ROP."

The aim of this study was to determine the association between poor "postnatal weight gain in babies" and incidence and severity of ROP.
\end{abstract}

\section{MATERIALS AND METHODS}

This was a prospective observational study, conducted over a period of 6 months at Govt. Rajaji Hospital, Madurai in 100 new born babies who fulfilled the inclusion exclusion criteria. The screening examination for ROP followed in our study was based on guidelines proposed by National Neonatology Forum (NNF). Relative weight gain is (Present weight - Birth weight) / (Birth weight $\mathrm{x}$ Chronological age in days) expressed in $\mathrm{g} / \mathrm{Kg} /$ day. The data were analysed with SPSS statistical software package, Version 16.0 SPSS Inc., Chicago, USA). Sample size was taken conveniently.

\section{RESULTS}

Among the 100 babies studied, incidence of ROP was 38\%. Incidence of severe ROP was 9\%. In 9 cases with severe ROP, 2 were treated with intravitreal bevacizumab and laser photocoagulation while 7 were treated with only laser photocoagulation. 12 babies for whom extremes of relative weight gain was observed were excluded in statistical analysis for obtaining precise results and all were in Group 1. Relative weight gain (g/kg/day) in both the groups at second, fourth and sixth weeks of postnatal life was calculated as mean \pm SD and were compared using unpaired student ' $t$ ' test at second, fourth and sixth week of postnatal life and all were found to be statistically significant with P-value of $<0.0001$.

\section{CONCLUSION}

The results of this study showed that "poor postnatal weight gain" in early postnatal period is a predictor for development of "severe ROP" requiring treatment with laser photocoagulation and/ or anti-VEGF in our hospital.

\section{KEYWORDS}

Post Natal, Prematurity Retinopathies, Childhood Blindness.

HOW TO CITE THIS ARTICLE: Senthil K, Soundharya S, Balasubramanian R, et al. A prospective study to find the association between poor postnatal weight gain and severe retinopathy of prematurity. J. Evolution Med. Dent. Sci. 2018;7(07):869-872, DOI: $10.14260 /$ jemds/2018/198

\section{BACKGROUND}

Retinopathy of Prematurity (ROP) is a disease affecting the retina of premature infants; and is one of the leading causes of preventable childhood blindness in India. ROP incidence in our country is between $38-52 \%$ among low birth weight babies. ${ }^{1}$

'Financial or Other Competing Interest': None.

Submission 14-11-2017, Peer Review 25-01-2018,

Acceptance 01-02-2018, Published 12-02-2018.

Corresponding Author:

Dr. Karupputhevar Senthil,

Associate Professor of Diabetology,

Eye Department OP No. 50,

Government Rajaji Hosptial, No. 1,

Panagal Road, Madurai-625020, Tamilnadu.

E-mail: eyedeptgrh@gmail.com

DOI: $10.14260 /$ jemds $/ 2018 / 198$

With improved neonatal care and better survival rate of preterm infants, ROP incidence in our country is on the increasing trend. The fundamental pathological process underlying ROP stems from incompletely vascularized peripheral retina at birth in preterm babies. After birth, ROP evolves slowly over 4-5 weeks and this gives us a small window of opportunity for predicting the development of severe ROP and timely interventions to improve visual outcome thereby avoiding irreversible blindness. ROP incidence increases with decreasing Gestational Age and Birth Weight, ${ }^{2}$ however not in all preterm babies. So, there might be other foetal and or maternal risk factors influencing the ROP development. These factors may protect or increase the probability of development of ROP.

According to revised Early Treatment of ROP Study (ETROP), ${ }^{3}$ approximately $8 \%$ screened babies require treatment 
based on current ROP screening guidelines. In more than $90 \%$ of babies ROP is either regressing or never developing. Although current ablation treatment reduces the incidence of blindness in babies with severe stages of ROP, these babies still have poor visual outcome and there exists significant impact of the disease on development of eye and vision. Recent studies showed that one of the strongest predictors of "severe ROP" is "poor postnatal weight gain" in early postnatal period. However, current screening protocols do not include this risk factor as a predictor for the development of ROP. Identifying a modifiable postnatal risk factor like "poor postnatal weight gain" by simple serial postnatal weight measurements helps in identification of premature babies at risk for developing severe ROP more specifically, thereby avoiding unnecessary stressful examination to babies not at risk, and also predicting the disease earlier before it is diagnosed by regular ocular examination that helps in early intervention and prevention of severe vision loss and unfavourable outcome.

\section{Aims and Objectives}

The aim of this study was to determine the association between poor "postnatal weight gain in babies" and incidence and severity of ROP.

\section{MATERIALS AND METHODS}

This was a prospective observational study, conducted over a period of 6 months in the Department of Ophthalmology and Institute of paediatrics at Govt. Rajaji Hospital, Madurai in 100 new born babies (both inborn and out born) who fulfilled the inclusion exclusion criteria. Babies born less than 34 weeks gestation and or babies born with birth weight less than 1750 grams were included in our study. Babies with non-physiological weight gain (due to hydrocephalus, congestive cardiac failure and hydrops), babies with obvious congenital anomalies and babies who expired before the completion of ROP screening were excluded. Informed consent was obtained from the parents or guardian of all the newborn babies included in our study. Sample size was taken conveniently.

Parameters recorded were infant's birth weight, gestational age at birth, post-conceptional age and other risk factors such as long-term exposure to oxygen, mechanical ventilation, surfactant use, respiratory distress syndrome, septicaemia, multiple blood transfusions, multiple births, apnoeic episodes and intraventricular haemorrhage. Gestational age was calculated according to the last menstrual period or first trimester abdomen sonogram.

The screening examination for ROP followed in our study was based on guidelines proposed by National Neonatology Forum (NNF). The first retinal examination was performed at 4 to 5 weeks of age. Ocular examinations were carried out by binocular indirect ophthalmoscope with +20 D lens, Figure: 1 , and findings were recorded in the ROP screening case sheet. Revised International classification of ROP 5 (ICROP) was used for categorization of ROP. Follow up examinations were based on the retinal findings and continued until complete vascularization or regressing ROP was noted or until treated based on the ETROP guidelines. In our study "mild ROP" was defined as ROP that does not meet criteria for treatment based on Cryotherapy for ROP study (CRYO-ROP)" and "ETROP study" guidelines and, "severe ROP" was defined as either Type 1 ROP based on "ETROP study" findings, threshold ROP, Aggressive posterior ROP (AP-ROP), stage 4 or stage 5 ROP that needs treatment.

Babies were divided into two groups. Group 1: Infants with no ROP and mild ROP. Group 2: Infants with "severe ROP". Infants were weighed unclothed before feed on calibrated electronic weighing machine with a digital read out. Infant's weight was recorded weekly till $4^{\text {th }}$ week and at $6^{\text {th }}$ week of post-natal age, and relative weight gain was calculated for the same. Relative weight gain is (Present weight - Birth weight) / (Birth weight $\mathrm{x}$ Chronological age in days) expressed in $\mathrm{g} / \mathrm{Kg} /$ day.

The data were analysed with SPSS statistical software package, Version 16.0 SPSS Inc., Chicago, USA). The relative weight gain was calculated for second week, fourth week and sixth week of postnatal age and compared between "no ROP/mild ROP" group and "severe ROP" group using unpaired student ' $\mathrm{t}$ ' test, logistic regression for severe prematurity was done with considering relative weight gain in different duration as an independent variable. $P$ value of $<0.05$ will be considered as statistically significant.

\section{RESULTS}

Among the 100 babies analysed, 43 were males and 57 were females. Group 1 had 39 males and 52 females while Group 2 had 4 males and 5 females. 88 were single gestation and 12 were twin gestation. Group 1 had 81 single gestation and 10 twin gestation babies and group 2 had 7 single gestation and 2 twin gestation babies. In group 1, mean gestational age at birth was $32.24 \pm 1.43$ weeks and ranged from $28-34$ weeks. In group 2, mean gestational age at birth was 29.9 \pm 1.04 weeks and ranged from 28-32 weeks Table 1. Two groups were compared using unpaired student ' $t$ ' test and found to be significant with $\mathrm{p}$-value of $<0.001$. In group 1 , mean birth weight was $1396.20 \pm 248.23$ grams ranged from 1000-1750 grams. In group 2, mean birth weight was $1164.44 \pm 140.99$ grams ranged from 930-1300 grams. Two groups were compared using unpaired student ' $\mathrm{t}$ ' test and found to be significant with $\mathrm{p}$-value of $<0.001$.

Among the 100 babies studied, incidence of ROP was $38 \%$ (38/100 babies had any stage of ROP). Incidence of severe ROP was $9 \%$ ( $9 / 100$ babies had severe ROP) Table 2. In the 9 cases with severe ROP, 2 were treated with intravitreal bevacizumab and laser photocoagulation while 7 were treated with only laser photocoagulation. 12 babies for whom extremes of relative weight gain was observed were excluded in statistical analysis for obtaining precise results and all were in Group 1. Relative weight gain ( $\mathrm{g} / \mathrm{kg} /$ day) in both the groups at second, fourth and sixth weeks of postnatal life was calculated as mean \pm SD and were compared using unpaired student ' $\mathrm{t}$ ' test at second, fourth and sixth week of postnatal life. The $\mathrm{p}$ - value $<0.001$ says that there is a statistical significant difference in the relative weight gain at each week between the No ROP/Mild ROP and Severe ROP groups Table 3 . Relative weight gain at $1^{\text {st }}, 2^{\text {nd }}, 3^{\text {rd }}, 4^{\text {th }}$ and $6^{\text {th }}$ week were put into logistic regression model and relative weight gain in the $1^{\text {st }}$ six weeks were found to be independently related to Severe Retinopathy of Prematurity, Table 4: 


\begin{tabular}{|c|c|c|}
\hline \multicolumn{2}{|c|}{ Characteristics } & Number (\%) \\
\hline \multirow{2}{*}{ Sex } & Male & $42(42)$ \\
\hline & Female & $58(58)$ \\
\hline \multirow{2}{*}{ Mode of delivery } & LSCS & $36(36)$ \\
\hline & NVD & $64(64)$ \\
\hline \multirow{2}{*}{ Type of Birth } & Single & $87(87)$ \\
\hline & Twin & $13(13)$ \\
\hline \multirow{3}{*}{ Birth Weight } & 500 to 1000 grams & $13(13)$ \\
\hline & 1000 to 1500 grams & $61(61)$ \\
\hline & Above 1500 grams & $26(26)$ \\
\hline \multirow{3}{*}{ Gestational Age } & 25 - 28 weeks & $5(5)$ \\
\hline & $29-32$ weeks & $51(51)$ \\
\hline & Above 32 weeks & $44(44)$ \\
\hline \multirow{9}{*}{$\begin{array}{l}\text { Maternal } \\
\text { Risk }\left(^{*}\right)\end{array}$} & None & $47(47)$ \\
\hline & Anaemia & $14(14)$ \\
\hline & Gestational Diabetes & $3(3)$ \\
\hline & PIH & $36(36)$ \\
\hline & Heart disease & $1(1)$ \\
\hline & Hypothyroid & $6(6)$ \\
\hline & Gestational Hypertension & $1(1)$ \\
\hline & Mean Birth weight @ & $\begin{array}{c}1375.35 \pm \\
237.78\end{array}$ \\
\hline & $\begin{array}{c}\text { Mean Gestational Age } \\
\text { (Weeks) @ }\end{array}$ & $32.03 \pm 1.623$ \\
\hline \multicolumn{3}{|c|}{$\begin{array}{c}\text { Table 1. Demographic and perinatal characteristics } \\
\text { of the } 100 \text { study neonates }\end{array}$} \\
\hline
\end{tabular}

${ }^{*}$ As there are multiple maternal risks, the total will be more than 100, @ Mean and Standard deviation

\begin{tabular}{|c|c|}
\hline Severity of ROP & N (\%) \\
\hline No ROP & $62(62)$ \\
\hline Mild ROP & $29(29)$ \\
\hline Severe ROP & $9(9)$ \\
\hline Total & $\mathbf{1 0 0}(100)$ \\
\hline Table 2. Tabulation for retinal findings \\
\hline
\end{tabular}

\begin{tabular}{|c|c|c|c|c|c|}
\hline \multirow{2}{*}{$\begin{array}{l}\text { Relative weight } \\
\text { gain (g/kg/day) }\end{array}$} & \multicolumn{2}{|c|}{$\begin{array}{c}\text { No ROP/Mild } \\
\text { ROP } \\
\end{array}$} & \multicolumn{2}{|c|}{ Severe ROP } & \multirow[b]{2}{*}{$P$ value ${ }^{T}$} \\
\hline & $\mathbf{N}$ & $\begin{array}{l}\text { Mean } \\
\text { (SD) }\end{array}$ & $\mathbf{N}$ & $\begin{array}{l}\text { Mean } \\
\text { (SD) }\end{array}$ & \\
\hline $\begin{array}{l}\text { Relative weight gain } \\
\text { at } 1^{\text {st }} \text { week }\end{array}$ & 91 & $\begin{array}{l}-7.53 \\
(4.58)\end{array}$ & 9 & $\begin{array}{l}-18.92 \\
(3.92)\end{array}$ & $<0.001$ \\
\hline $\begin{array}{l}\text { Relative weight gain } \\
\text { at } 2^{\text {nd }} \text { week }\end{array}$ & 91 & $\begin{array}{l}-2.73 \\
(3.96)\end{array}$ & 9 & $\begin{array}{l}-9.23 \\
(3.92)\end{array}$ & $<0.001$ \\
\hline $\begin{array}{l}\text { Relative weight gain } \\
\text { at } 3^{\text {rd }} \text { week }\end{array}$ & 91 & $\begin{array}{c}0.83 \\
(3.93) \\
\end{array}$ & 9 & $\begin{array}{c}-6.5 \\
(1.98) \\
\end{array}$ & $<0.001$ \\
\hline $\begin{array}{l}\text { Relative weight gain } \\
\text { at } 4^{\text {th }} \text { week }\end{array}$ & 91 & $\begin{array}{c}4.03 \\
(4.61)\end{array}$ & 9 & $\begin{array}{l}-3.11 \\
(0.9)\end{array}$ & $<0.001$ \\
\hline $\begin{array}{l}\text { Relative weight gain } \\
\text { at } 6^{\text {th }} \text { week }\end{array}$ & 91 & $\begin{array}{c}8.52 \\
(5.48)\end{array}$ & 9 & $\begin{array}{l}-0.97 \\
(0.87) \\
\end{array}$ & $<0.001$ \\
\hline \multicolumn{6}{|c|}{$\begin{array}{c}\text { Table 3. Table showing significance of relative weight gain } \\
\text { in different types of ROP }\end{array}$} \\
\hline
\end{tabular}

T-Unpaired student's t test.

\begin{tabular}{|c|c|c|c|}
\hline Parameter & $\begin{array}{c}\text { Odds } \\
\text { Ratio }\end{array}$ & $\begin{array}{c}\text { 95\% Confidence } \\
\text { Interval }\end{array}$ & $\begin{array}{c}\mathbf{p} \text { - } \\
\text { value }\end{array}$ \\
\hline $\begin{array}{c}\text { Relative weight gain at } \\
\text { 1st week }\end{array}$ & 0.703 & $0.58-0.84$ & $<0.001$ \\
\hline $\begin{array}{c}\text { Relative weight gain at } \\
\text { 2nd week }\end{array}$ & 0.69 & $0.56-0.86$ & 0.001 \\
\hline $\begin{array}{c}\text { Relative weight gain at } \\
\text { 3rd week }\end{array}$ & 0.55 & $0.403-0.77$ & $<0.001$ \\
\hline $\begin{array}{c}\text { Relative weight gain at } \\
\text { 4th week }\end{array}$ & 0.62 & $0.48-0.81$ & 0.001 \\
\hline $\begin{array}{c}\text { Relative weight gain at } \\
\text { 6th week }\end{array}$ & 0.47 & $0.31-0.73$ & 0.001 \\
\hline
\end{tabular}

Table 4. Logistic regression for severe prematurity taking relative weight gain at different duration as an independent variable

\section{DISCUSSION}

ROP is caused by abnormal retinal vascular development in postnatal period. Identifying postnatal factors which have a predictive value in development and severity of ROP will be helpful for ROP screening and prevention. Clinical and animal studies showed that "low serum levels of IGF-1" and "poor postnatal weight gain" are associated with development of "severe form of ROP". Foundation for ROP screening is timely detection and treatment of severe ROP to get better visual outcome. Weekly measurements of weight in early postnatal period helps in detection of babies at risk for developing severe ROP weeks before may have significant positive effect on care of these babies and predicting severe ROP in babies requiring deferment or rescheduling of ocular examination.

Allagaert et al study ${ }^{4}$ showed poor absolute weight gain (g/day) but not relative weight gain in first 6 weeks of life was associated with threshold disease. Fortes Filho et al study 5 showed low weight gain proportion at 6 weeks of life is an independent risk factor for development of ROP requiring treatment.

These studies were different from our present study in that they used absolute weight gain or weight gain proportion in their studies. However, these have limitations in reflecting the true weight gain, because these premature babies were all born with different birth weights, and smaller babies are expected to have lower weight gain compared to larger babies. Therefore, the more appropriate definition is relative weight gain.

This study calculated relative weight gain at second, fourth and sixth weeks of life and found that "poor relative weight gain at the second, fourth and sixth week of life was capable of predicting the development of severe ROP requiring treatment". This is supported by study by Wallace et al and it showed that GA and poor relative weight gain in first 6 weeks of postnatal life were independent risk factors for development of $\geq$ stage 3 ROP.

Aydemir et al also used a similar method and they found relative weight gain in $4^{\text {th }}$ week of life was independently lower in babies with severe form of ROP. An online surveillance system was developed in Sweden based on BW measurements and serum IGF-1 levels weekly in the neonates. Weight IGF-1 Neonatal ROP (WINROP) algorithm was designed to detect the slow rise in IGF-1 levels or weight gain and was compared with values of infants those who have no ROP or only stage 1 ROP. It has $100 \%$ sensitivity in 
detecting babies who will need treatment for ROP. Later it was modified that only serial weight measurements part of WINROP algorithm, excluding IGF-1 measurement was used, that can also predict severe ROP requiring treatment with $100 \%$ sensitivity. This algorithm was validated in Sweden and USA in a different cohort of infants. In 2015 July, American Academy of Ophthalmology published evolving concepts in diagnosis and management of ROP, included poor postnatal weight gain as independent risk factor for developing ROP.

IGF-1 is essential for the normal growth and development of many tissues including brain, retina and blood vessels. Preterm babies have lower serum IGF-1 level after birth due to poor endogenous production and loss of maternal source of IGF. Sepsis, intraventricular haemorrhage, bronchopulmonary dysplasia, and necrotizing enterocolitis, all acts via common pathway that reduces IGF-1 level and are associated with development of ROP. Serum IGF-1 concentration is strongly associated with postnatal weight gain and development of ROP in preterm babies. Postnatal weight gain is used as a surrogate measure for serum IGF-1 level. This explains the association of relative weight gain at the early postnatal period and development of severe ROP. This new approach helps to reduce the number of babies requiring stressful eye examination for ROP and precisely targeting babies at risk of developing severe ROP. This method helps to take more regulated follow up measures for babies with high risk to ensure visit compliance, decreasing the unfavourable outcome from missed ROP appointments as it is cost effective and readily available.

Early postnatal nutrition is important for postnatal weight gain. Human milk increases infants IGF-1 level and omega 3 fatty acid level that protect against ROP. New pharmacological treatments to improve physiologic retinal vascularization e.g. omega 3-polyunsaturated fatty acid supplementation, IGF-1 supplementation, erythropoietin supplementation have shown good results in animal studies, but more work is needed before considered for use in preterm infants. Many randomized clinical trials found the essential nutrient, inositol, to reduce the severity of ROP.

\section{Limitation of the Study}

Due to short duration of study sample size was also calculated by convenience.

\section{CONCLUSION}

The results of this study showed that "poor postnatal weight gain" in early postnatal period is a predictor for development of "severe ROP" requiring treatment with laser photocoagulation and/ or anti-VEGF in our hospital. It helps in the prediction of the ROP much earlier in infants with poor postnatal course who are at the risk of developing severe ROP with possibility of new preventive treatment and avoids unnecessary stressful examination in preterm infants who are not at the risk of developing severe ROP.

Thus, ophthalmologists and neonatologists should take special care and give more attention to the babies with poor postnatal weight gain to predict the disease much earlier before it is diagnosed by regular ocular examination that helps in early intervention and prevention of sight threatening complications.

\section{REFERENCES}

[1] Rasoulinejad SA, Montazeri M. Retinopathy of prematurity in neonates and its risk factors: a seven year study in Northern Iran. Open Ophthalmol J 2016;10:17-21.

[2] Darlow BA, Hutchinson JL, Simpson JM, et al. Variation in rates of severe retinopathy of prematurity among neonatal intensive care units in the Australian and New Zealand Neonatal Network. Br J Ophthalmol 2005;89(12):1592-6.

[3] Jones JG, MacKinnon B, Good WV, et al. The early treatment for ROP (ETROP) randomized trial: study results and nursing care adaptations. Insight 2005;30(2):7-13.

[4] Aydemir 0, Sarikabadayi YU, Aydemir C, et al. Adjusted poor weight gain for birth weight and gestational age as a predictor of severe ROP in VLBW infants. Eye (Lond) 2011;25(6):725-9.

[5] Wang ZH, Gao PF, Bai H, et al. Postnatal weight gain in very low birth weight infants in Beijing and the risk of retinopathy of prematurity. Int $\mathrm{J}$ Ophthalmol 2015;8(6):1207-10. 